\title{
$\begin{array}{ll}\text { Research Square } & \text { Preprints are preliminary reports that have not undergone peer review. } \\ \text { They should not be considered conclusive, used to inform clinical practice, }\end{array}$ or referenced by the media as validated information. \\ Optimal Design of a Helical Coil Support for Dewars in Fuel Cell Applications
}

\section{Baby Nitin}

Indian Institute of Technology Kharagpur

Pavitra Sandilya ( $\nabla$ profsandilya@gmail.com )

Indian Institute of Technology Kharagpur https://orcid.org/0000-0002-4982-9130

\section{Goutam Chakraborty}

Indian Institute of Technology Kharagpur

\section{Research Article}

Keywords: Fuel Cell, Dewars, Liquid Oxygen, Genetic Algorithm, Optimization, Helical Coil

Posted Date: August 24th, 2021

DOl: https://doi.org/10.21203/rs.3.rs-770941/v1

License: (1) This work is licensed under a Creative Commons Attribution 4.0 International License.

Read Full License

Version of Record: A version of this preprint was published at Environmental Science and Pollution Research on April 22nd, 2022. See the published version at https://doi.org/10.1007/s11356-022-20286-y. 


\title{
Optimal design of a helical coil support for dewars in fuel cell applications
}

\author{
Baby Nitin ${ }^{1}$, Pavitra Sandilya ${ }^{1 *}$, Goutam Chakraborty ${ }^{2}$ \\ ${ }^{1}$ Cryogenic Engineering Centre, Indian Institute of Technology Kharagpur, Kharagpur, West \\ Bengal, India, 721302 \\ ${ }^{2}$ Department of Mechanical Engineering, Indian Institute of Technology Kharagpur, Kharagpur, \\ West Bengal, India, 721302 \\ * profsandilya@gmail.com; +917501384731
}

\begin{abstract}
Fuel cells are gaining popularity because of their efficient energy production without causing environmental pollution. Recently DRDO, has developed a fuel cell-based fuel cell-based Air Independent Propulsion (AIP) system. In this system, the hydrogen is produced onboard while oxygen is carried in liquified form (LOX) from the land in specially designed insulated storage vessels called dewars. Such vessels are needed because LOX has low boiling point (NBP $\sim 90 \mathrm{~K})$ and heat of vaporization $(\sim 213 \mathrm{~kJ} / \mathrm{kg})$ due to which it boils off easily even when there is small amount of heat inleak from the ambient. A typical dewar consists of two vessels separated by insulation. Support members are used to hold the two vessels together. Heat inleak through the supports and the insulation of the dewar causes the boiling of LOX. The vessels are subjected to dynamic loads during the voyage as well as due to the filling and consumption of LOX. Therefore, the support system should be designed so that it can withstand the dynamic loads experienced by the dewar. While the support system should have enough mechanical strength to withstand the loads it is subjected to, it should also restrict the heat inleak from the ambient to minimize the LOX boil-off. To meet this requirement, we need to optimize the support system design. Design optimization of support systems is especially critical in submarines to reduce the snorkeling frequency. Even though the dewars are available commercially for various applications, their design methodologies are not available in the open literature. Cylindrical rods are generally used as support members. In earlier studies, the authors have shown that helical coils give better thermal performance than tension rods as dewar supports. These two support systems involve different design criteria. It is important to evolve an optimal design of the support system to maximize the mechanical strength of the support while minimizing the heat inleak through the support. In this paper we are presenting a design methodology for optimizing a helical support. We have proposed a modified optimization technique derived from the classical genetic algorithm (GA) for this purpose. The modification has been done by ensuring design feasibility of the coil at each step of the algorithm. The proposed optimization technique has been tested on a LOX dewar and an optimal design of the helical coil support has been obtained.
\end{abstract}

Keywords: Fuel Cell, Dewars, Liquid Oxygen, Genetic Algorithm, Optimization, Helical Coil 


\section{Introduction:}

Submarines are important strategic and surveillance vehicles employed by navies of the world. Their missions require them to be underwater for long durations of time. Energy production for propulsion and running auxiliary systems while submerged is challenging. Most power sources require atmospheric oxygen to work and produce gases that need to be removed. Air is taken in tanks in the submarine to be utilized during underwater maneuvering. However, the submarine has to surface (snorkel) to refill the tank to maintain the amount of air in this tank. Snorkeling increases the chances of detection of the submarine by enemy anti-submarine warfare machines (Benedict 2005). Another challenge is the disposal of the waste gases produced. Waste gases are generally hotter than seawater. Releasing these gases into the sea creates a thermal footprint of the submarine that can be detected by anti-submarine drones (Ya'ari 1997). Air-independent propulsion (AIP) is gaining popularity for submarine applications due to these reasons (de-Troya et al. 2016). Two of the feasible AIP technologies are nuclear and fuel cell based. Nuclear energy sources have high reliability, high efficiency, and have very high energy density for the fuel mass carried. However, nuclear submarines pose dangers of nuclear radiation and leak. Disposal of used nuclear fuel from submarines is also challenging as they cause adverse effects on life and the environment. Fuel cell AIP systems are relatively safer compared to nuclear AIPs. A typical fuel cell requires $\mathrm{O}_{2}$ and $\mathrm{H}_{2}$ to operate.

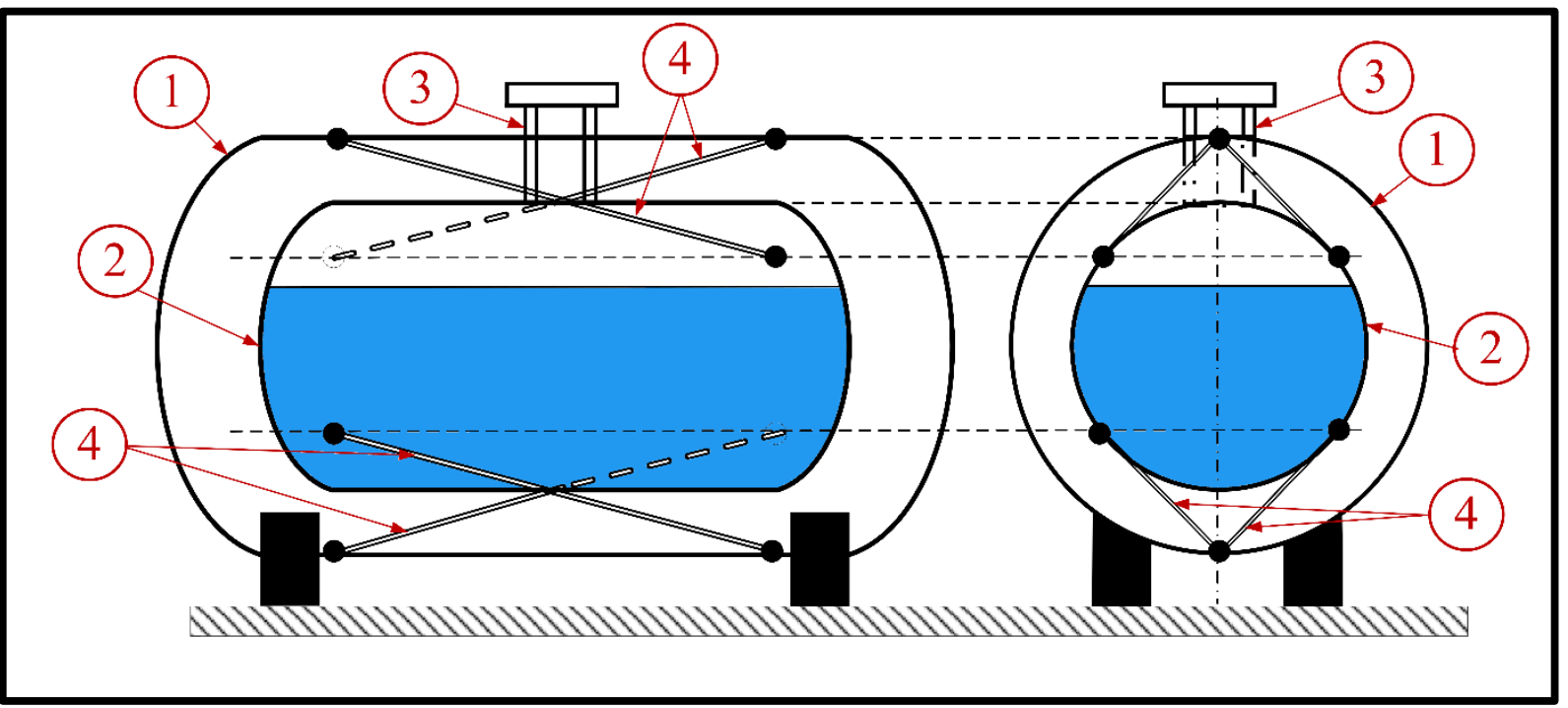

Figure 1. Construction of a typical dewar showing the major components. (1)- Outer Vessel, (2) - Inner Vessel, (3) - Input/ Output vent, (4) - Support members, Black circles represents the support- dewar fixture locations.

$\mathrm{O}_{2}$ is generally taken from the land in its liquid phase (Liquid oxygen-LOX) to reduce the storage space required (For the same given volume, the mass of LOX stored is about 800 times more than that of gaseous $\mathrm{O}_{2}$ ). As $\mathrm{O}_{2}$ liquefies below $123 \mathrm{~K}$, it is termed as a cryogen. As LOX has a low boiling point (NBP of LOX $\sim 90 \mathrm{~K}$ ) and a low enthalpy of vaporization (LOX $\sim 213 \mathrm{~kJ} / \mathrm{kg}$ ), it gets vaporized easily. Vaporization (boil-off) of LOX increases the pressure in the storage tank. The boil-off gases are either utilized or vented to prevent tank rupture. Since the fuel cell requires the input gases to be in their gaseous phase, boil-off gases can be effectively utilized. However, such utilization is only possible when the boil-off is less than or equal to the requirement of the cell.

In most cases, venting the boil-off is the only possible solution to avoid over-pressurization. Venting of oxygen directly into the sea poses great strategic and environmental problems. The temperature of boil-off LOX is lower than the sea temperature. Venting LOX boil-off causes ice formation on the vent port of the submarine that creates back pressure to the vented boil-off LOX stream. This back pressure may lead to increased pressure in the LOX tanks. Also, venting leaves a cold trail in the sea, leading to the detection of the submarine. In addition, venting LOX boil-off increases the amount of oxygen concentration in the sea, thereby leading to gas bubble disease in fishes and reducing photosynthesis by aquatic plants. 
Furthermore, venting LOX is the loss of available oxidizer quantity for the fuel cell. Loss of oxidizer calls for frequent refilling of the LOX tank, thus reducing the mission time of the submarine. In order to tackle these issues, it is pertinent to develop LOX storage systems that prevent boil-off.

Since its introduction in 1898 (Foerg 2002), the dewar vessel has been the most popular storage medium for cryogens. Dewar is essentially a double-walled container with the annular space filled with high-efficiency insulations such as MLI or evacuated powder insulation (Barron 1985). Fig. 1 shows the construction of a typical dewar vessel.

The inner and outer vessels of the dewar are connected using support members. These support members hold the vessels in place under the action of various loads while resisting movements in all six degrees of freedom (UX, UY, UZ, ROTX, ROTY, ROTZ). Apart from these mechanical loads, the support members also tend to undergo thermal contraction during the cool-down phase of the dewar. Support members are pre-tensed during installation to neutralize the effects of thermal contraction. For achieving the desired strength and ease in welding, these members are usually fabricated using the same material of construction $(\mathrm{MoC})$ as the tanks. As the tank material is usually metallic (SS304 or SS316), support members made of such high thermal conductivity MoC create a thermal short between the vessels. This thermal short facilitates the easy ingress of heat into the cryogen from the ambient. It was stated that about $50 \%$ of heat inleak into the cryogen in the dewar is through the support members (Jacob 1993). However, a recent study showed that the contribution of supports towards heat inleak is much higher (Nitin et al. 2021b).

Nevertheless, an ineffective support system can nullify the effect of a good insulation system. Due to these reasons, the support members need to be designed for minimum heat inleak and maximum mechanical strength. Mechanical strength of different support systems is evaluated in terms of realized factor of safety (RFOS), which is the ratio of the maximum stress generated in the support to the yield strength of the MoC. Slender cylindrical rods are generally used as dewar supports. Cylindrical rods withstand greater tensile loads compared to other cross-sections of the same area (Barron 1985). Straps and struts as dewar supports have been studied and designed for space-borne dewars (Kittel 1993; Reed et al. 1997). They are highly specialized for aeronautical systems and cannot be applied for submarines. Concentric cylinders, posts, stacked plates, and helical coils are some other reported dewar supports. Apart from these, a few patented designs of dewar supports are available (Hibl 1975; Silver 1985). These designs are application specific and difficult to fabricate. In addition, the steps involved in their design are not obvious. To the best of the authors' knowledge, a comprehensive design methodology of dewar support is not available in the open literature.

100

101

102

103

Studies on helical coils as dewar supports were recently reported (Virdi et al. 2019; Nitin et al. 2020, Nitin et al. 2021a). In these studies, comparisons were made between cylindrical rod support and helical support in their mechanical and thermal performances. It was found that the latter had superior thermal and inferior mechanical strength compared to the former.

The performances of the helical coil are functions of its wire diameter, coil diameter, and pitch. Several helical coils can be generated by varying these parameters. An optimized set of these dimensions are to be found to design efficient support. Also, the dimensions of the supports are dependent on the dimensions of the dewar itself (inner and outer vessel diameters and inner vessel length). This dependence has not been reported in the literature. These have been derived in the present work. The present work optimizes the design of helical coils used as dewar supports with objectives to maximize the mechanical strength and minimize the heat inleak through the supports.

The optimization problem is multi-variate and multi-objective. Also, as all the combinations of the variables need not generate coils, the objective functions are discontinuous. The optimization cannot be done using the traditional optimization techniques such as the steepest descent method (Fliege et al. 2000), conjugate descent method (Dai et al. 2003), random walk method (Bertsimas et al. 2004), etc., as these methods fail in the presence of discontinuities (Pratihar 2007). Further, the optima derived from these classical techniques are highly dependent on the initial solution considered, and the solution may get trapped in a local basin. Because of these reasons, a non-traditional optimization strategy is used while tackling this problem. Genetic Algorithm (GA) (Deb 1998), Simulated Annealing (SA) (Kirkpatrick et al. 1983), Ant Colony Optimization (ACO) (Dorigo 1999), Particle Swarm 
Optimization (PSO) (Poli et al. 2007), etc. are some examples of non-traditional optimization algorithms. GA has previously been successfully used in finding the optima in several problems in mechanical (Subramanian et al. 2013), chemical (Yu et al. 2002), and thermal engineering (Mohebbi et al. 2008; Ahmadzadeh et al. 2017; Saha et al. 2018) fields. In the present work, a modified GA has been used as an optimization tool. Modifications are made to the typical GA to ensure that the solution is geometrically feasible and prevent the solution from getting stuck in local basins.

\section{Modeling:}

Optimization studies need a knowledge of the system behavior. Therefore, the mechanical and thermal behavior of the support system has been modeled to arrive at the objective functions for optimization.

\section{Mechanical Performance Model:}

For modeling the mechanical performance of the helical coil supports, their RFOS is found. The model assumptions are:

1. $\mathrm{MoC}$ is isotropic and homogeneous (Sadd 2009)

2. Supports are in tension due to the applied loads (Barron 1985)

3. Load is equally distributed amongst the supports

4. The dewar is completely cooled down

The free-body diagram of coil support, under the application of loads, are shown in Fig. 2

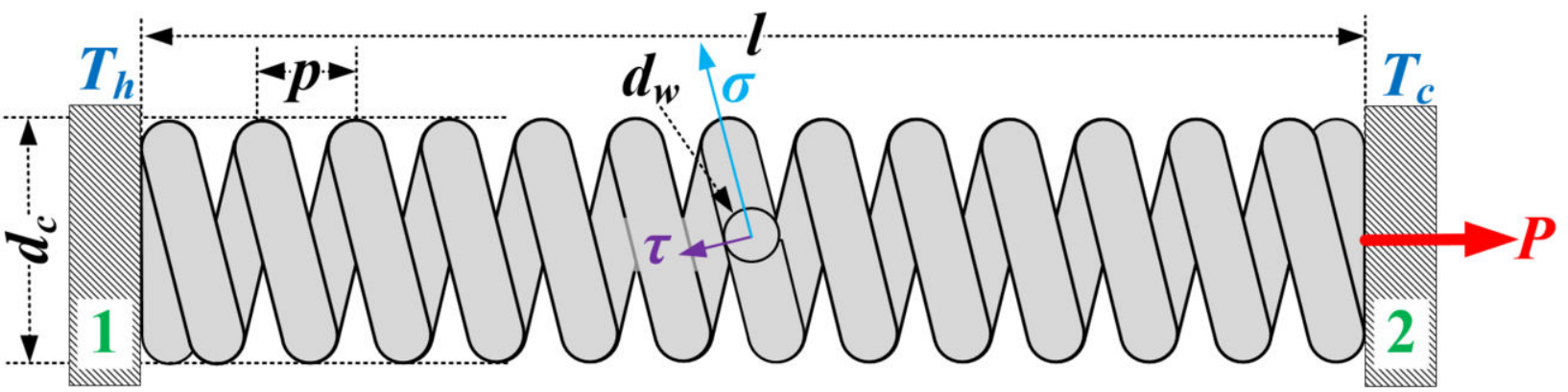

Figure 2. Free body diagrams of a cylindrical rod support and a coil support under the application of load $P$. $d_{w}$ is the wire diameter, $d_{c}$ is the coil diameter and $l$ is the length of the support. $T_{h}$ is the temperature of the outer vessel and $T_{c}$ is the cryogen temperature. (1) and (2) are the faces of the support in contact with the outer and inner vessels respectively.

As per assumption (4), the thermal stresses generated in the support are completely compensated by their pretension. The mechanical load and the stress thus generated are elaborated in the following sections.

\section{Mechanical load:}

Dynamic load on the support is dictated by the weight of the cryogen in the tank (Barron 1985; Nitin and Sandilya 2018), given by

$$
P_{\text {total }}=8 P_{\text {static }}=8 m_{\text {liquid }} g=8 \rho_{\text {LOX }} V_{\text {liquid }} g
$$

By assumption (3), the mechanical load acting on an individual support is,

$$
P=\frac{P_{\text {total }}}{n}
$$

Where $n$ is the number of support members.

\section{Mechanical stress in helical coil support:}

A load acting on the helical coil in the direction of the axis of the coil generates two types of stresses on the coil. (1) Tensile stress $(\sigma)$ acting along the wire axis of the coil, (2) Shear stress $(\tau)$ acting perpendicular to the axis of the wire axis. Tensile and shear stresses are found as (Shigley et al. 2008),

$$
\tau=\frac{8 P d_{c}}{\pi d_{w}^{3}}
$$

and 
The coil support fails when either of the stresses exceeds the yield strengths of the material. The RFOS is thus derived as,

\section{Thermal Performance Model:}

$$
R F O S=\min \left[\frac{\sigma}{\sigma_{y s}}, \frac{\tau}{\tau_{y s}}\right]
$$

Subjected to the constraints,

The thermal performance of the supports is a measure of the heat ingress the support allows through it. To model this, we find the heat transfer occurring through the supports. The following assumptions are made:

1. The MoC of the support is homogeneous and isotropic; this is true for the considered MoC (SS304).

2. Heat transfer is steady state, i.e., the dewar has cooled down.

3. Heat transfer through the support is predominantly 1-D along the axis of the support wire; this is true as the considered MoC (SS304) of the support has high thermal conductivity, and the length of the support wire in the axial is more than that in the radial direction.

The temperature distribution in the support (shown in Fig. 3) is found by solving the steady state 1-D energy balance equation given by,

$\frac{\partial}{\partial x}\left[k \frac{\partial T}{\partial x}\right]=0$

(Eqn. 6)

$$
\text { At } x=0 ; T=T_{H} \text { and at } x=l_{\text {heat }} ; T=T_{C}
$$

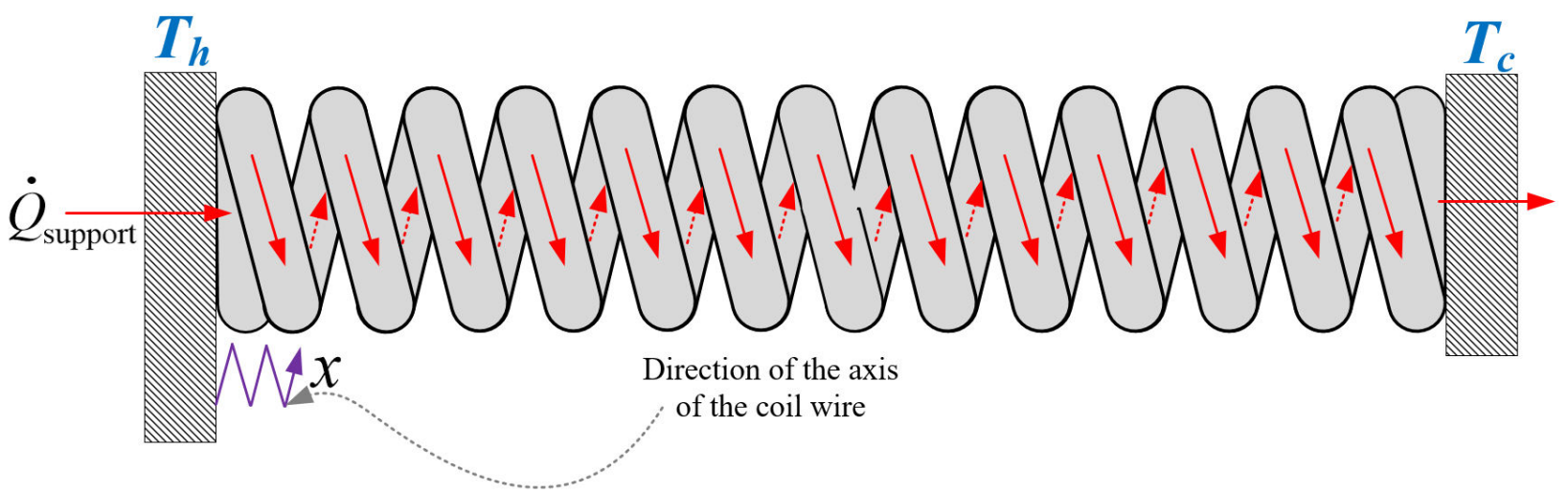

Figure 3. Schematic diagram of the support showing the length direction and the temperatures

The heat inleak through the support is obtained by solving Fourier's law of conduction.

$$
\dot{Q}_{\text {support }}=k \frac{\pi d_{w}^{2}}{4} \frac{d T}{d x}
$$

For most materials used at cryogenic temperature, thermal conductivity is a function of temperature (He et al. 2019). The variation of thermal conductivity has been incorporated in the model. Discreet values of thermal conductivities at cryogenic temperatures are tabulated in the literature (Bradley and Radebaugh 2013). These values are regressed as (Nitin et al 2020),

$$
k(T)=A_{1} T+A_{2}
$$

To determine the boil-off rate of the stored LOX, mass and energy conservation are applied within the inner vessel. 


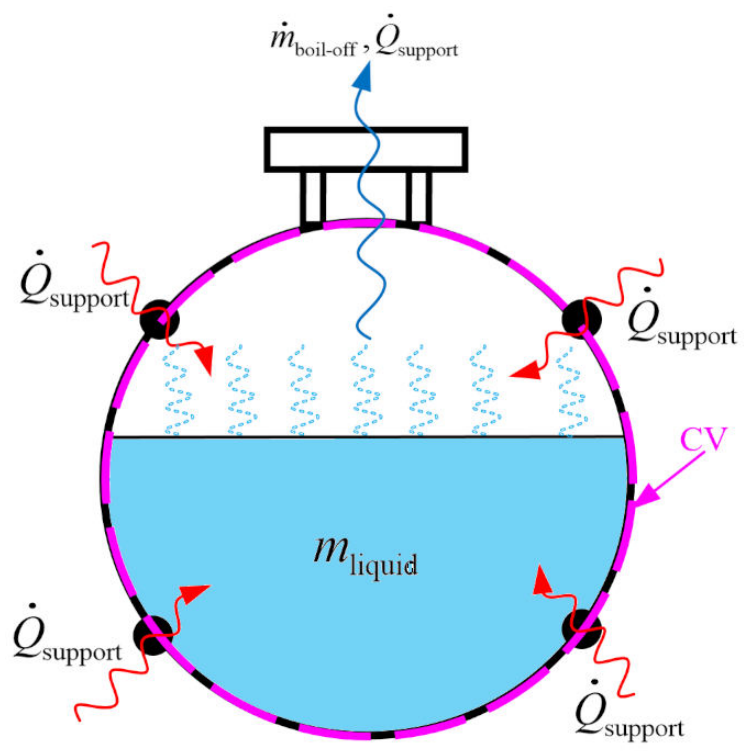

Mass balance applied to the $\mathrm{CV}$ is written as,

$$
\frac{d m_{\text {liquid }}}{d t}=\dot{m}_{\text {boil-off }}
$$

The mass remaining in the $\mathrm{CV}$ at any time can be computed subjecting Eqn. 9 to,

$$
\text { At } t=0, m_{\text {liquid }}=m_{\text {liquid }, 0}
$$

As per assumption (4) the energy balance equation is written as,

$$
n \dot{Q}_{\text {support }}=\dot{Q}_{\text {boil-off }}
$$

The rate of liquid mass boil-off is found from,

$$
\dot{m}_{\text {boil-off }}=\frac{\dot{Q}_{\text {boil-off }}}{h_{f g}}
$$

\section{Dependence of support dimensions on dewar size:}

Support members can be attached to the inner and outer vessels at any location. However, to increase the thermal length between the vessels, the supports are attached diagonally in the annular space of the dewar. Figure. 5 shows

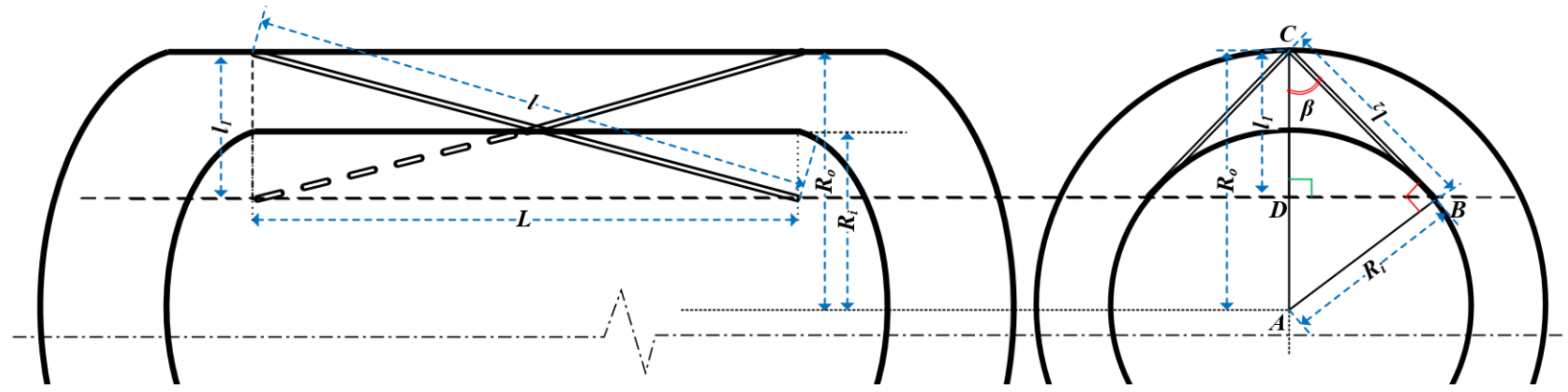

Figure 5. Configuration of the support in the annular space of the vessel.

The axial length of the support is derived as, 
In $\Delta^{\mathrm{le}} \mathrm{ABC}$

$$
\begin{gathered}
A C^{2}=A B^{2}+B C^{2} \\
B C=\sqrt{A C^{2}-A B^{2}} \\
l_{2}=\sqrt{R_{o}^{2}-R_{i}^{2}} \\
\beta=\tan ^{-1}\left(\frac{R_{i}}{R_{o}}\right)
\end{gathered}
$$

In $\Delta^{\mathrm{le}} \mathrm{BCD}$

$$
\begin{gathered}
\frac{l_{1}}{l_{2}}=\cos (\beta) \\
l_{1}=l_{2} \cos \left(\tan ^{-1}\left(\frac{R_{i}}{R_{o}}\right)\right) \\
l=L^{2}+l_{1}^{2} \\
l=\sqrt{L^{2}+\left(\sqrt{R_{o}^{2}-R_{i}^{2}} \cos \left(\tan ^{-1}\left(\frac{R_{i}}{R_{o}}\right)\right)\right)^{2}}
\end{gathered}
$$

A heat transfer length of the support is the length of the stretched coil given by Lingaiah (2003),

$$
l_{\text {heat }}=\pi d_{c}\left(\frac{l-d_{w}}{p}\right)
$$

\section{Objective function:}

As mentioned before, the optimal coil has maximum RFOS and minimum $\dot{Q}_{\text {support }}$. For this, Eq. 5 is to be maximized, and Eq. 7 is to be minimized. GA, by definition, is a maximizing technique (Pratihar 2007). Minimizing Eq. 7 has to be reframed into a maximization problem for the implementation of GA. Equation 13 shows the conversion strategy used in the present work,

$$
\dot{Q}_{\text {support }}^{*}=\frac{1}{1+\dot{Q}_{\text {support }}^{2}}
$$

Since the optimization problem is multi-objective, a hybrid fitness function is formulated using linear scalarization as,

$$
f\left(d_{w}, d_{c}, p\right)=w_{1} \text { RFOS }+w_{2} \dot{Q}_{\text {support }}^{*}
$$

$f$ represents the hybrid fitness function which includes the combined mechanical and thermal performance of the supports. The weights $w_{1}$ and $w_{2}$ define the contribution of each of these performances on the hybrid fitness function.

Variables and constraints:

Wire diameter of the coil $\left(d_{w}\right)$ :

The minimum wire diameter, is that which is just sufficient to sustain the loads if the support were a cylindrical rod. This diameter is found as,

The maximum wire diameter, is that which can execute at least two turns within the length of the support. This 227

$$
\min \left(d_{w}\right)=\sqrt{\frac{4 P}{\pi \sigma_{y s}}}
$$
diameter is found as, 
229 Coil diameter $\left(\boldsymbol{d}_{c}\right)$ :

230 The fusing of the wires of the coil reduces the thermal distance between the ends of the support. The minimum coil diameter is that which prevents the radial fusing of the wires. This coil diameter is found as,

$$
\min \left(d_{c}\right)=2 d_{w}
$$

The maximum coil diameter is the radius of the annular space.

$$
\max \left(d_{c}\right)=\Delta R
$$

Pitch $(p)$ :

To prevent the axial fusing of the wires of the coil, the minimum pitch is twice the diameter of the wire.

$$
\min (p)=d_{w}
$$

The maximum pitch is that which executes two turns of the coil wire. This pitch is found as,

$$
\max (p)=\frac{l-d_{w}}{2}
$$

The constraints are summarized in Table 1 .

Table 1. Limits of the variables

\begin{tabular}{|c|c|c|}
\hline Variables & Minimum Value & Maximum Value \\
\hline $\boldsymbol{d}_{\boldsymbol{w}}$ & $\sqrt{(4 P) /\left(\pi \sigma_{y s}\right)}$ & $l-2 p$ \\
\hline $\boldsymbol{d}_{\boldsymbol{c}}$ & $2 d_{w}$ & $\Delta R$ \\
\hline $\boldsymbol{p}$ & $d_{w}$ & $\left(l-d_{w}\right) / 2$ \\
\hline
\end{tabular}

\section{Representation of an individual:}

In GA, the variable value is called a gene. A chromosome is a set of genes. An individual chromosome in the present problem hence has three genes. There are various established ways of encoding the variable values (Meng et al. 1999) into the chromosome. In this work, binary encoding is utilized. The advantage of binary encoding is that computer systems can handle binary faster than real numbers. In order to achieve a resolution of at least 1000 for each of the variables, a 10-bit binary encoding (resolution of 1024) has been used for each gene; Fig. 6 shows such an encoded chromosome.

A group of individual chromosomes is known as the population. $N_{\text {pop }}$ represents the number of individuals in a population. The chromosomes in the initial generation are populated by using a time-dependent positive random number generator. Any generator output less than 0.5 is set as 0 ; else is set as 1 .

Usually, in GA, the variable constraints are fixed numerical values with no dependence on the other variable values. However, as seen from Table. 1 this is not true in the present study. One needs to ensure that only the feasible individuals are allowed to become the optimized value. Infeasible individuals can be removed by imposing a penalty on their fitness values. This imposition happens after the initial generation is populated. There is a chance that the initial population may contain several infeasible individuals. These individuals would be rejected based on their fitness value, thus producing no undesirable effect on the solution. However, as the number of such infeasible individuals in the initial population increases, there is a chance that only a limited number of feasible individuals propagates into subsequent generations. Reduction in the number of feasible individuals lowers the chances of the GA converging towards the actual global optima. Global maxima in such cases may be reached by increasing the probability of mutation. However, increasing the probability of mutation may reduce the algorithm's efficiency and render it similar to a random search technique. In the present work, a novel method to overcome the issue under study has been employed. While populating the initial generation, the feasibility of the variables is checked for each 
individual, and the infeasible individuals are removed. This method ensures that the number of individuals in the

\begin{tabular}{|l|l|l|l|l|l|l|l|l|l|l|l|l|l|l}
\hline $\mathbf{1}$ & $\mathbf{0}$ & $\mathbf{0}$ & $\mathbf{1}$ & $\mathbf{0}$ & $\mathbf{0}$ & $\mathbf{1}$ & $\mathbf{1}$ & $\mathbf{0}$ & $\mathbf{1}$ & Gene corresponding to wire diameter
\end{tabular}

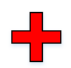

\begin{tabular}{|l|l|l|l|l|l|l|l|l|l|l|}
\hline $\mathbf{0}$ & $\mathbf{1}$ & $\mathbf{1}$ & $\mathbf{1}$ & $\mathbf{1}$ & $\mathbf{1}$ & $\mathbf{0}$ & $\mathbf{0}$ & $\mathbf{1}$ & $\mathbf{0}$ & Gene corresponding to coil diameter \\
\hline
\end{tabular}

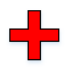

\begin{tabular}{|l|l|l|l|l|l|l|l|l|l|l|l|}
\hline $\mathbf{0}$ & $\mathbf{0}$ & $\mathbf{1}$ & $\mathbf{0}$ & $\mathbf{1}$ & $\mathbf{1}$ & $\mathbf{0}$ & $\mathbf{1}$ & $\mathbf{0}$ & $\mathbf{0}$ & Gene corresponding to coil pitch \\
\hline
\end{tabular}

\section{\begin{tabular}{|l|l|l|l|l|l|l|l|l|l|l|l|l|l|l|l|l|l|l|l|l|l|l|l|l|l|l|l|l|l|}
$\mathbf{1}$ & $\mathbf{0}$ & $\mathbf{0}$ & $\mathbf{1}$ & $\mathbf{0}$ & $\mathbf{0}$ & $\mathbf{1}$ & $\mathbf{1}$ & $\mathbf{0}$ & $\mathbf{1}$ & $\mathbf{0}$ & $\mathbf{1}$ & $\mathbf{1}$ & $\mathbf{1}$ & $\mathbf{1}$ & $\mathbf{1}$ & $\mathbf{0}$ & $\mathbf{0}$ & $\mathbf{1}$ & $\mathbf{0}$ & $\mathbf{0}$ & $\mathbf{0}$ & $\mathbf{1}$ & $\mathbf{0}$ & $\mathbf{1}$ & $\mathbf{1}$ & $\mathbf{0}$ & $\mathbf{1}$ & $\mathbf{0}$ & $\mathbf{0}$ \\
\hline
\end{tabular}}

\section{Chromosome of an individual}

\section{Selection:}

Figure 6. Representation of binary encoded genes and the chromosome of an individual

GA is an iterative process, and each iteration is called a generation. As per the theory of evolution, the succeeding generations have better average fitness compared to their parents. The fitness improves because the desirable traits of the parents are handed over to their offspring. To ensure this, only certain "eligible" parents are allowed to mate and reproduce. Eligibility is based on the fitness of the parents. Choosing the eligible parents is called selection. GA has several selection methods like tournament selection, probability selection or roulette wheel selection, ranking selection, elitism, etc. (Lim and Haron 2013). In this work, tournament selection is used as this method is computationally faster compared to the other methods. In tournament selection, a fixed number of parent chromosomes are selected from the population. The fittest parent from this selection is sent to the mating pool; this process is called a tournament. In order to keep the number of individuals in the generations same, $N_{\text {pop }}$ number of tournaments are conducted.

\section{Reproduction:}

Reproduction is the process by which two parent chromosomes in the mating pool combine to produce offsprings. The crossover operator performs reproduction. The crossover operator slices both the parents' chromosomes and stitches one parents' chromosome with the complementary chromosome of the other parent. Thus one crossover produces two offspring. A two-point crossover (Hongze et al. 2000) operator acting at chromosome length locations 10 and 20 is employed in this work. The crossover may yield a chromosome whose offsprings are infeasible. These offspring need to be removed. In this work, offspring are checked for their feasibility post crossover. If they are feasible, then crossover takes place, else the parents continue to the next generation as themselves. It is also possible that the feasible offsprings produced by crossover have less fitness than their parents. In order to prevent the undesirable effect this may have on the algorithm, some parents continue to proceed to the next generation as themselves. The decision if parents undergo cross over or not is made based on a probability constant $\left(P_{c}\right)$.

\section{Mutation:}

In natural evolution, it can be observed that certain offspring have characteristics, which belong to neither of their parents. Deviation in the characters of the individuals occurs due to "mutation". In any optimization procedure, there is a chance that the solution proceeds towards a local optimum. In GA, this is avoided by inducing an abrupt change in the genome of the individual. In the present study, mutation may produce infeasible offsprings. The feasibility of an individual is checked post mutation. If the individual is feasible, mutation proceeds; if the individual is infeasible, the mutation is reversed. Too much mutation reduces the efficiency of GA by making it proceed 
similar to a random walk method. In order to prevent this, the decision if an individual will be mutated or not is decided based on the mutation probability constant $\left(P_{m}\right)$.

Evolution proceeds until the maximum fitness of individuals in successive generations converges. After convergence, the individual having maximum fitness in the last generation will have the optimal variables. However, there is still a small chance that the GA might have stuck at local maxima. In order to add an extra layer of protection against this, the mutation operator acts on a few randomly selected individuals $\left(N_{m u t}\right)$ of the final generation. Suppose these mutated individuals have fitness less than the maximum fitness value. In that case, the maxima found from the previous step is taken as the final optima. Suppose any of these individuals have fitness greater than the maximum fitness. In that case, multiple copies of the mutated individuals are added to the population. The complete algorithm of the process is shown in Figure 7.

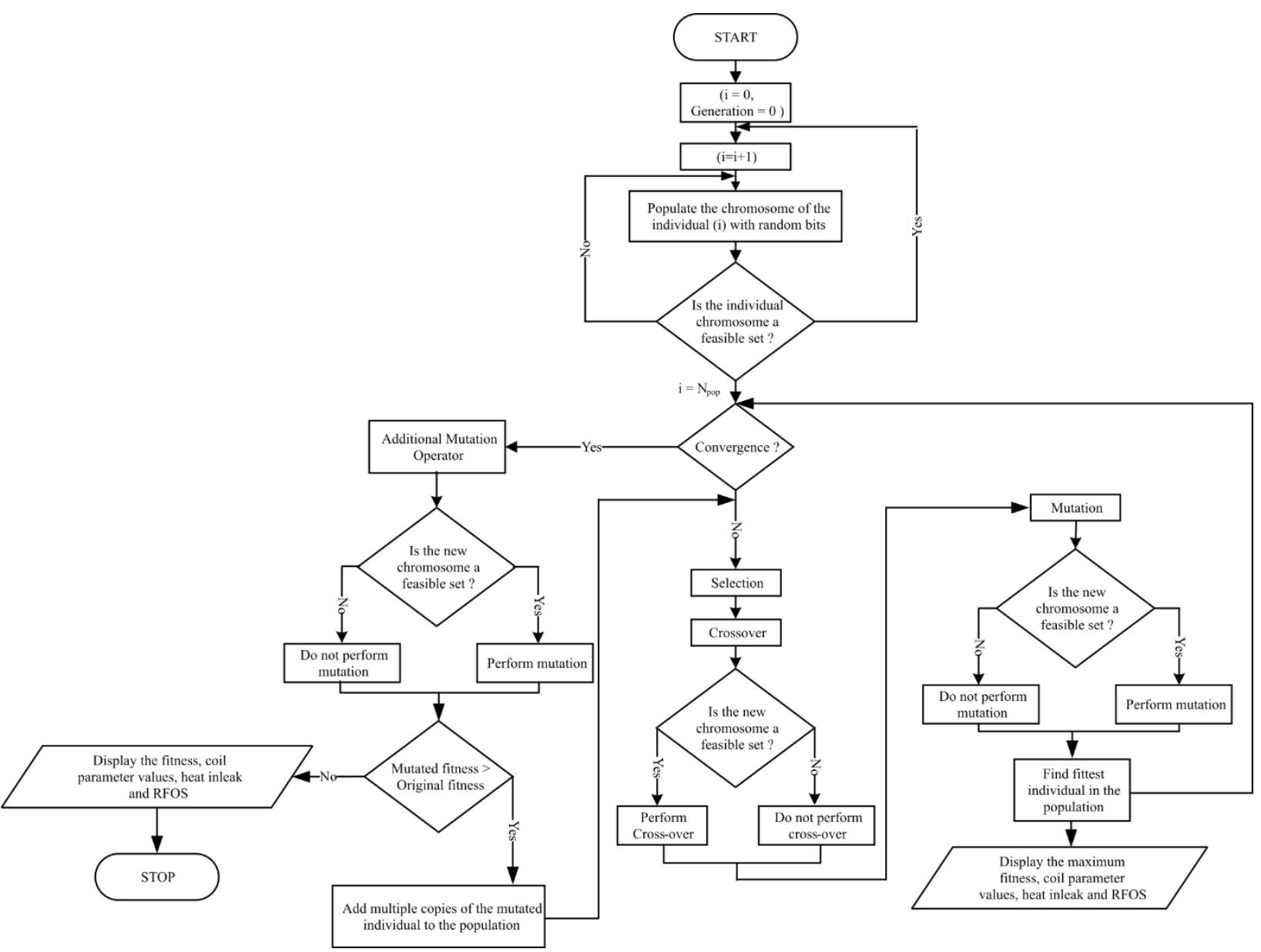

Figure 7. Flow chart of the amended GA used to find the optimum coil dimensions

Selection of the GA parameters:

$P_{c}$ and $P_{m}$ should be carefully chosen so that the algorithm converges faster. In this work, the algorithm is run on a small pilot population, varying one of the probabilities keeping the other constant. That value of the probability which gives the maximum fitness is chosen as the optimal value of probability. The algorithm is run on the test population using these optimal values of probabilities.

\section{Results and discussion:}

To illustrate the proposed optimization method, we considered a hypothetical cylindrical dewar of MoC SS 304 . The dewar is filled with saturated LOX at $1 \mathrm{~atm}$. In order to restrict all the six degrees of freedom (UX, UY, UZ, ROTX, 
ROTY, ROTZ), six supports are employed (Barron 1985). The dimensions of the considered vessels are summarized in Table 2.

3

Table 2. Vessel dimension of the hypothetical LOX vessel

\begin{tabular}{|c|c|c|}
\hline Dimension & & Value \\
\hline Radius of the outer vessel & $R_{o}$ & $850 \mathrm{~mm}$ \\
\hline Radius of the inner vessel & $R_{i}$ & $500 \mathrm{~mm}$ \\
\hline Length of the inner vessel & $L$ & $2 \mathrm{~m}$ \\
\hline Number of supports & $n$ & 6 \\
\hline
\end{tabular}

The total load acting on the support system is found as per Eqn.1,

$$
P_{\text {total }}=8 \rho_{\text {LOX }} \pi R_{i}^{2} L g=140.8 \mathrm{kN}
$$

The load acting on a single support member, $P$ is found using Eqn.2.

$$
P=\frac{140.8}{6} k N=23.5 \mathrm{kN}
$$

The length of the support is obtained as,

$$
l=2086 \mathrm{~mm}
$$

The temperature of LOX in the vessel is $90 \mathrm{~K}$. The ambient temperature is taken as $300 \mathrm{~K}$. The constants used for thermal conductivity evaluation as per Eqn. 8 are given in Table 3.

Table 3. Value of constants in the regressed thermal conductivity equation

\begin{tabular}{|l|c|c|}
\hline Material & $\boldsymbol{A}_{\mathbf{1}}$ & $\boldsymbol{A}_{\mathbf{2}}$ \\
\hline SS 304 & 0.0328 & 5.8436 \\
\hline
\end{tabular}

An in-house $\mathrm{C}++$ program was developed to implement the optimization procedure. GA parameters used in this work are tabulated in Table 4. The plots showing the variation of fitness for various values of $P_{c}$ and $P_{m}$ are shown in Fig.8 and Fig. 9 respectively.

Table 4. GA Parameters used in this work

\begin{tabular}{|c|c|}
\hline Parameter & Value \\
\hline$N_{\text {pop }}$ & 10,000 \\
\hline$P_{c}$ & 0.7 \\
\hline$P_{m}$ & 0.02 \\
\hline
\end{tabular}

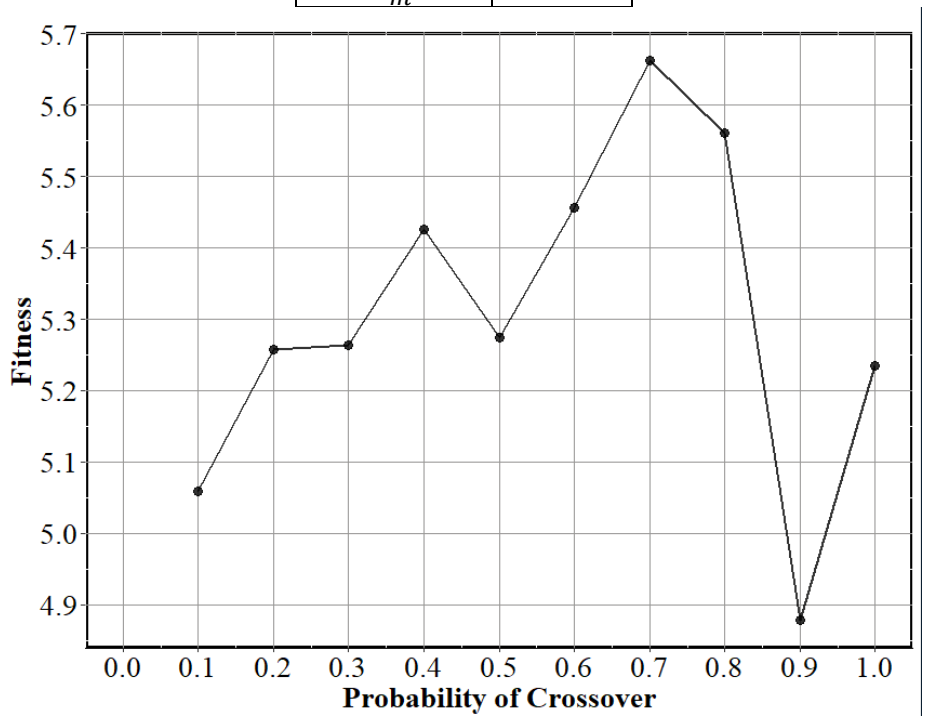

Figure 8. Fitness corresponding to various values of $P_{c}$ 


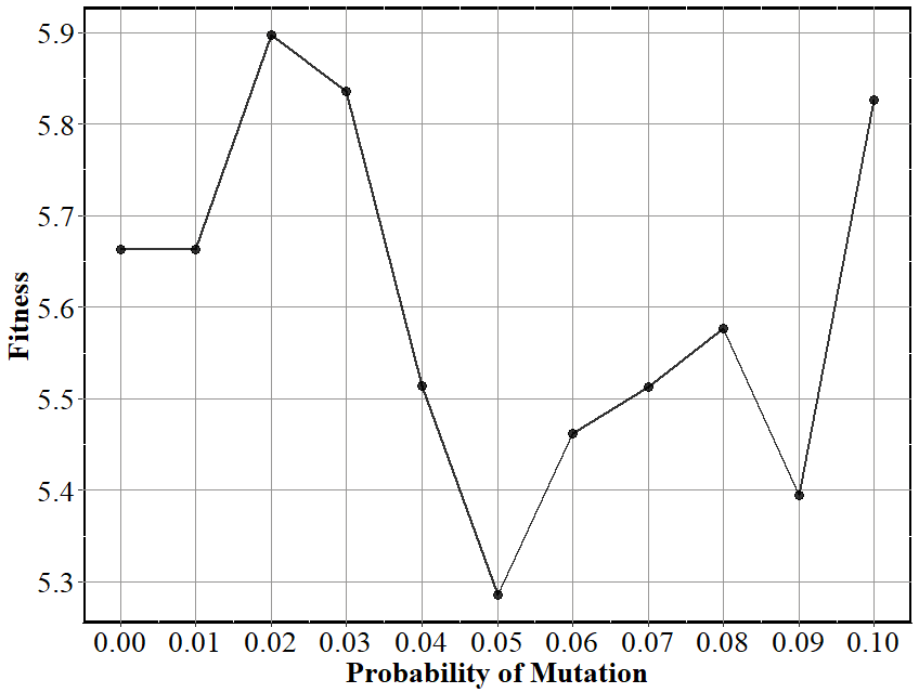

Figure 9. Fitness corresponding to various values of $P_{m}$

After convergence of the algorithm, the coil geometry variables are obtained as $d_{w}=118.5 \mathrm{~mm}, d_{c}=298 \mathrm{~mm}$ and $p=123.5 \mathrm{~mm}$. A CAD geometry of the optimized coil is shown in Fig. 10

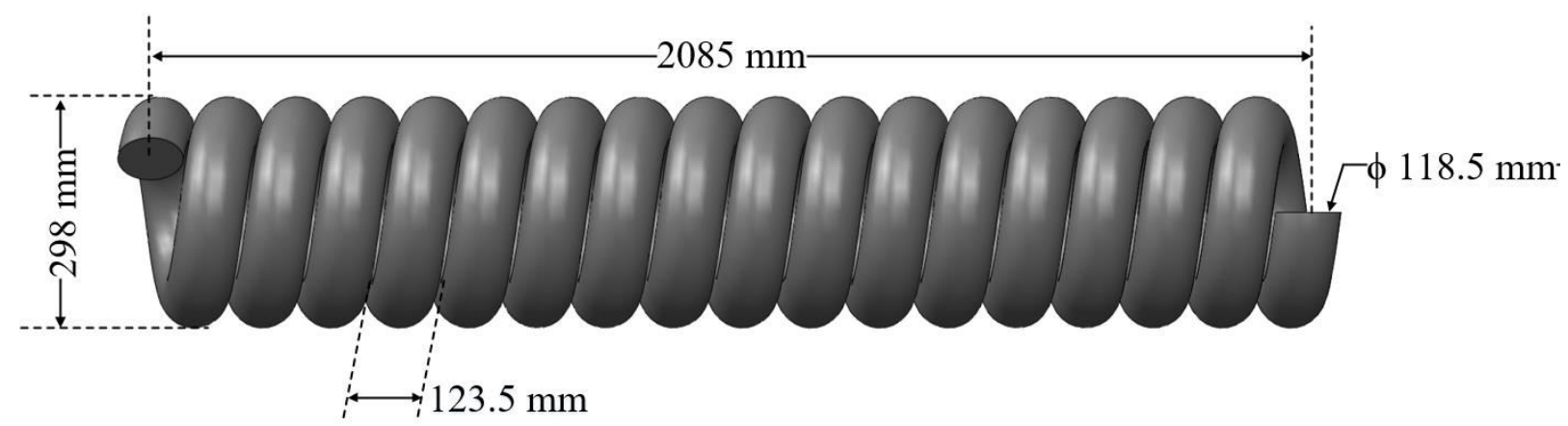

Figure 10. CAD drawing of the optimized coil geometry

We now check the closeness of the optimized variables to the limits of the variables.

According to Eq.17 and Eq.18 the lower and upper limits of $d_{c}$ are,

$$
\min \left(d_{c}\right)=237 \mathrm{~mm}: \max \left(d_{c}\right)=350 \mathrm{~mm}
$$

The optimized value of $d_{c}$ is closer to the lower limit (46\%) of the variable.

According to Eq.15 and Eq.16 the lower and upper limits of $d_{w}$ are,

$$
\min \left(d_{w}\right)=11.8 \mathrm{~mm}: \max \left(d_{w}\right)=1838 \mathrm{~mm}
$$

The optimized value of $d_{w}$ is closer to the lower limit (6\%) of the variable.

According to Eq.19 and Eq.20 the lower and upper limits of $p$ are,

$$
\min (p)=118.5 \mathrm{~mm}: \max (p)=983.2 \mathrm{~mm}
$$

The optimized value of $p$ is closer to the lower limit $(0.6 \%)$ of the variable.

The closeness of the variables to the lower limit suggests that the optimized coil tends towards a closed coil tension spring. However, a closed coil tension spring cannot be used as dewar supports as the contact between the coils would create a thermal short between the vessels. Jacketed closed helical coils can be effectively employed as dewar supports. The thermal and mechanical performances of the optimized coil are given in Table 5.

Table 5. Performances of the optimized helical coil support

\begin{tabular}{|l|c|c|c|}
\hline Support & Heat inleak (W) & RFOS & Boil-off rate (x10 $\left.{ }^{-5} \mathbf{k g} / \mathbf{s}\right)$ \\
\hline Optimized helical coil & 1.9 & 11.6 & 5.35 \\
\hline
\end{tabular}

\section{Conclusions:}

In this work we optimized the design of a helical coil dewar support. A modified version of the classical GA was employed as the optimization tool. Feasibility of the coil and global optima were ensured in the optimization process. Some of the salient contributions of this work are: 
1. Relationship between the support length and the dewar dimensions were derived for the first time.

2. Inter relationship between the dimensions of the coil have been derived in the work

3. A multiobjective multivariable fitness function was developed for the optimization of dewar support design.

\section{References:}

Ahmadzadeh, A., Salimpour, M. R., \& Sedaghat, A. (2017). Thermal and exergoeconomic analysis of a novel solar driven combined power and ejector refrigeration (CPER) system. International Journal of refrigeration, 83, 143 156. https://doi.org/10.1016/j.ijrefrig.2017.07.015

Barron, R. F. (1985). Cryogenic systems. New York: Oxford University Press.

Benedict, J. R. (2005). The unraveling and revitalization of US Navy antisubmarine warfare. Naval War College Review, 58(2), 93-120.

Bertsimas, D., \& Vempala, S. (2004). Solving convex programs by random walks. Journal of the ACM (JACM), 51(4), 540-556. https://doi.org/10.1145/1008731.1008733

Bradley, P. E., \& Radebaugh, R. (2013). Properties of selected materials at cryogenic temperatures. NIST Publ, 680, $1-14$.

Dai, Y. H., \& Ni, Q. (2003). Testing different conjugate gradient methods for large-scale unconstrained optimization. Journal of Computational Mathematics, 311-320.

Deb, K. (1998). Genetic algorithm in search and optimization: the technique and applications. In Proceedings of International Workshop on Soft Computing and Intelligent Systems, (ISI, Calcutta, India) (pp. 58-87). Proceedings of International Workshop on Soft Computing and Intelligent Systems, (ISI, Calcutta, India).

de-Troya, J. J., Alvarez, C., Fernández-Garrido, C., \& Carral, L. (2016). Analysing the possibilities of using fuel cells in ships. International Journal of Hydrogen Energy, 41(4), 2853-2866. https://doi.org/10.1016/j.ijhydene.2015.11.145

Dorigo, M., \& Di Caro, G. (1999). Ant colony optimization: a new meta-heuristic. In Proceedings of the 1999 congress on evolutionary computation-CEC99 (Cat. No. 99TH8406) (Vol. 2, pp. 1470-1477). IEEE. https://doi.org/10.1109/CEC.1999.782657

Fliege, J., \& Svaiter, B. F. (2000). Steepest descent methods for multicriteria optimization. Mathematical methods of operations research, 51(3), 479-494. https://doi.org/10.1007/s001860000043

Foerg, W. (2002). History of cryogenics: the epoch of the pioneers from the beginning to the year 1911. International journal of refrigeration, 25(3), 283-292. https://doi.org/10.1016/S0140-7007(01)00020-2

He, J., Guo, Y., Miao, J., Ding, T., Zhang, H., Chen, Y., \& Lin, G. (2019). Pre-flight thermal performance test of a $35 \mathrm{~K}$ cryogenic integrated system. International Journal of Refrigeration, 98, 372-380. https://doi.org/10.1016/j.ijrefrig.2018.11.020

Hibl, J. J., \& Sutton, H. E. (1975). U.S. Patent No. 3,905,508. Washington, DC: U.S. Patent and Trademark Office.

Hongze, X., Ye, W. X., \& Maosheng, X. (2000). Schema analysis of multi-points crossover genetic algorithm. In Proceedings of the 3rd World Congress on Intelligent Control and Automation (Cat. No. 00EX393) (Vol. 1, pp. 521-524). IEEE. https://doi.org/10.1109/WCICA.2000.860022

Jacob, S., Kasthurirengan, S., \& Karunanithi, R. (1993). Concentric tubular support design for cryogenic tanks. Cryogenics, 33(4), 435-437. https://doi.org/10.1016/0011-2275(93)90173-L

Kirkpatrick, S., Gelatt, C. D., \& Vecchi, M. P. Optimization by simulated annealing. science. 1983 May 13; 220 (4598): 671-80.

Kittel, P. (1993). Comparison of Dewar supports for space applications. Cryogenics, 33(4), 429-434. https://doi.org/10.1016/0011-2275(93)90172-K

Lim, S. P., \& Haron, H. (2013). Performance of different techniques applied in genetic algorithm towards benchmark functions. In Asian Conference on Intelligent Information and Database Systems (pp. 255-264). Springer, Berlin, Heidelberg. https://doi.org/10.1007/978-3-642-36546-1_27

Lingaiah, K. (2003). Machine design databook. McGraw-Hill Education.

Meng, Q. C., Feng, T. J., Chen, Z., Zhou, C. J., \& Bo, J. H. (1999). Genetic algorithms encoding study and a sufficient convergence condition of GAs. In IEEE SMC'99 Conference Proceedings. 1999 IEEE International 
Conference on Systems, Man, and Cybernetics (Cat. No. 99CH37028) (Vol. 1, pp. 649-652). IEEE. https://doi.org/10.1109/ICSMC.1999.814168

Mohebbi, A., Taheri, M., \& Soltani, A. (2008). A neural network for predicting saturated liquid density using genetic algorithm for pure and mixed refrigerants. International Journal of Refrigeration, 31(8), 1317-1327. https://doi.org/10.1016/j.ijrefrig.2008.04.008

Nitin, B., \& Sandilya, P. (2018). Structural and thermal analysis of dewar supports for low boil-off long duration storage of cryogenic liquids. Indian Journal of cryogenics, 43(1), 33-39, https://doi.org/10.5958/23492120.2018.00005.5

Nitin, B., Sandilya, P., \& Chakraborty, G. (2020). Design of dewar supports through topology optimization. In IOP Conference Series: Materials Science and Engineering (Vol. 755, No. 1, p. 012054). IOP Publishing. https://doi.org/10.1088/1757-899X/755/1/012054

Nitin, B., Sandilya, P., \& Chakraborty, G. (2021a). Theoretical Comparison of the Thermo-Mechanical fatigue characteristics of a tension rod and coil used as dewar supports. Presented at CEC/ICMC 21, 17-23 July 2021.

Nitin, B., Sandilya, P., \& Chakraborty, G. (2021b). Revisiting the dewar design for liquid oxygen storage in fuel cell energy systems. Manuscript submitted for publication.

Poli, R., Kennedy, J., \& Blackwell, T. (2007). Particle swarm optimization. Swarm intelligence, 1(1), 33-57. https://doi.org/10.1007/s11721-007-0002-0.pdf

Pratihar, D. K. (2007). Soft computing. Alpha Science International, Ltd.

Reed, R. P., \& Golda, M. (1997). Cryogenic composite supports: a review of strap and strut properties. Cryogenics, 37(5), 233-250. https://doi.org/10.1016/S0011-2275(97)00004-0

Sadd, M. H. (2009). Elasticity: theory, applications, and numerics. Academic Press.

Saha, P., Nitin, B., \& Sandilya, P. (2018). Optimization of the performance of injection cooling system using genetic algorithm. Indian Journal of Cryogenics, 43(1), 16-21. https://doi.org/10.5958/2349-2120.2018.00002.X

Shigley, J. E., Mischke, C. R., Budnyas, R. G., \& Nisbett, K. J. (2008). Shigley'S Mechanical Engineering Design (In Si Units). Tata McGraw-Hill.

Silver, D. M., \& Dehaas, N. (1985). U.S. Patent No. 4,496,073. Washington, DC: U.S. Patent and Trademark Office.

Subramanian, M., Sakthivel, M., Sooryaprakash, K., \& Sudhakaran, R. (2013). Optimization of cutting parameters for cutting force in shoulder milling of Al7075-T6 using response surface methodology and genetic algorithm. Procedia Engineering, 64, 690-700. https://doi.org/10.1016/j.proeng.2013.09.144

Virdi, P. S., Nitin, B., Sandilya, P., \& Chakraborty, G. (2019). Theoretical comparison of thermo-mechanical behavior of a tension rod and a coil as dewar support. https://doi.org/10.5958/2349-2120.2019.00038.4

Ya'ari, Y. (1997). A Case for Maneuverability. Naval War College Review, 50(4), 125-132. Retrieved July 24, 2021, from http://www.jstor.org/stable/44638783

Yu, H., Fang, H., Yao, P., \& Yuan, Y. (2000). A combined genetic algorithm/simulated annealing algorithm for large scale system energy integration. Computers \& Chemical Engineering, 24(8), 2023-2035. https://doi.org/10.1016/S0098-1354(00)00601-3 


\section{Declarations}

\section{Ethics approval and consent to participate: \\ Not Applicable}

\section{Consent for publication}

Not applicable

Availability of data and materials

Not applicable

\section{Competing interests}

The authors have no financial or proprietary interests in any material discussed in this article.

\section{Funding}

The authors did not receive support from any organization for the submitted work.

\section{Authors' contributions}

- BN - Conceptualization, Methodology, Investigation, Formal Analysis, Visualization, Writing - Original Draft.

- PS - Conceptualization, Methodology, Investigation, Formal Analysis, Resources, Visualization, Writing Review \& Editing, Supervision, Project administration.

- GC - Writing - Review \& Editing, Supervision.

\section{Acknowledgements}

We acknowledge National Supercomputing Mission (NSM) for providing computing resources of 'PARAM Shakti' at IIT Kharagpur, which is implemented by C-DAC and supported by the Ministry of Electronics and Information Technology (MeitY) and Department of Science and Technology (DST), Government of India.

\section{Authors' information}

B. Nitin is at present a research scholar pursuing doctoral studies in the field of storage and transport of liquid cryogens.

Pavitra Sandilya is a faculty of Cryogenic Engineering Centre. He works in the fields of carbon capture and utilization, natural gas, energy storage, storage and transport of cryogenic fluids.

Goutam Chakraborty is a faculty of Department of Mechanical Engineering. He works in the fields of mechanics of advanced materials, MEMS, NEMS, vibration and noise control, recovery and storage of cryogenic liquids. 